\title{
Effect of Ionic Liquids on Vapor Liquid Equilibrium of Methanol + Ethyl acetate
}

\author{
Anand V.P. Gurumoorthy ${ }^{\mathrm{a}, 1}$, Nagamalleswara Rao. K $\mathrm{K}^{\mathrm{b}, 2,}, \mathrm{M}^{\mathrm{*}}$ Aslam Abdullah ${ }^{\mathrm{a}, 3}$, \\ Raj Saurabh a,4, O V Aadil Hussain a,5, Mahesh Jayan a,6

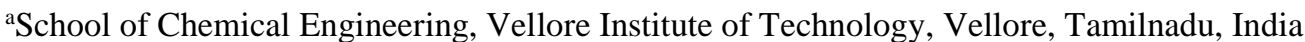 \\ ${ }^{\mathrm{b}}$ Centre for Disaster Mitigation and Management(CDMM), Vellore Institute of Technology, Vellore, Tamilnadu, India \\ E-mail: ${ }^{2}$ nagamalleswara.rao@vit.ac.in
}

Received 2 August 2019, Revised 16 December 2019, Accepted 18 December 2019

\begin{abstract}
The objective of this research work is to determine the effect of ionic liquids on the vapor liquid equilibrium behaviour of methanol and ethyl acetate binary system at atmospheric pressure. The ionic liquids used in the experiments are: 1-ethyl-3-methylimidazolium Chloride [EMIM][Cl], 1-ethyl-1-methylpyrrolidinium Bromide [EMPyrr][Br]. Vapour-liquid equilibrium (VLE) experiments were conducted with Othmer still experimental setup and the VLE data sets were tested for thermodynamic consistency. The average deviations of experimental results were within the experimental toleration limits and satisfied the Gibbs-Duhem equation. The results showed that the addition of ionic liquids (ILs) caused salting-out effect of methanol from the system. For the same concentrations of the ionic liquids, [EMIM][Cl] is observed to be more effective than the [EMPyrr] $[\mathrm{Br}]$ in breaking the azeotropes and in increasing the salting effect. For the $15 \%$ concentration of [EMPyrr][Br] the azeotrope was completely disappeared.
\end{abstract}

Keywords: Methanol; Ethyl acetate; Ionic liquids; Vapor liquid equilibrium.

\section{Introduction}

One percent error in measuring the thermodynamic vapour liquid equilibrium data leads to a hundred percent failure of the final designs of industrial equipment's and finally it can lead to industrial disasters. In this context while designing the industrial operations especially the more energy consumed equipment's like separation equipment and the reactors more care should be taken. Separation of azeotrope is one the challenging area in designing the separation equipment. In the conceptual design stage if errors occurred in predicting the vapour-liquid equilibrium (VLE), it leads to huge energy and economic losses. Especially in the case of azeotrope compositions, Methanol and ethyl acetate mixture is one that kind mixture.

Coming to the importance of this study, the worldwide consumption of methanol is steadily increasing steadily. The reason for this demand is it is used as a starting material for the production of various products like acids, acetates, acrylates, amines fuel additives, aldehydes [1-4]. In the production of biodiesel methanol is used for the transesterification reaction and ethyl acetate is used in interesterification reaction [5-7]. Ethyl acetate and methanol mixture is used in the pharmaceutical industry for the preparation of substances used for medical treatment. Ethyl acetate is used as solvent in industrial operations and it forms azeotrope with methanol $[8,9]$. To separate the azeotrope extractive distillation is the mostly used technique [10-11]. Extracting agent influences the cost of the equipment used in the separation [12-13]. Non-corrosive, non-toxic and having low vapor pressure are the features of the Ionic liquids which makes them as a good choice as extracting agent [16-18]. Various studies [19-24] reported the advantages of the Ionic liquids (ILs) as extractive agents.
From the open literature, it has been identified that methanol and ethyl acetate forms a minimum boiling azeotropic mixture. Several research have been done on breaking the mixture using salt and ionic liquid, but very few of them has had successful result on the system. The combination of ionic liquids like 1-ethyl-3methylimidazolium diethylphosphate ([EMIM][DEP]) and 1-butyl-3-methylimidazolium dibutylphosphate ([BMIM][DBP]) are used as entrainers to break the azeotrope by Zhang et al [24] and they succeeded in breaking the azeotropes. This work motivated the present study to investigate the effect of ionic liquids, like 1-ethyl-1methylpyrrolidinium Bromide ([EMPyrr][Br]) and 1-ethyl3-methylimidazolium Chloride([EMIM][Cl]) at different concentrations in breaking the azeotropic mixture of methanol and ethyl acetate.

\section{Experiments \\ 2.1 Materials}

Methanol (99.0 wt \%) was supplied by Titan Biotech Ltd., Rajasthan. Ethyl acetate was obtained from Nice Chemicals Private Ltd., Cochin with purity 99.0 wt \%. Calcium chloride, [EMPyrr][Br] and [EMIM][Cl] were procured from Sigma Aldrich Corp., Bengaluru. An anhydrous salt was used for the experiment. The digital LCD thermometer temperature test pen as shown in Figure 1 was supplied by Electromania Digital.

\subsection{Method}

Vapour-liquid equilibrium (VLE) data of methanolethyl acetate system at isobaric condition was determined by VLE setup supplied by New Venus Industries, Chennai, India maintained at atmospheric pressure and it is shown in 
Figure 2. The apparatus consists of a still connected to a condenser with reflux. The system is heated using a thermostat, with a heating temperature range of 0 to $100^{\circ} \mathrm{C}$. The reboiler was a $500 \mathrm{ml}$ capacity round bottom flask. The neck is heated externally using a nichrome wire. The chamber is completely surrounded by the cooling water jacket with water pumped continuously throughout the procedure.

For methanol-ethyl acetate system, different mixtures of calculated concentrations were prepared ranging from 0 to 1.0 mole fraction of methanol with intervals of $0.1 .100 \mathrm{ml}$ solution of methanol and ethyl acetate was added to the still with known compositions. Methanol volume considered as v $\mathrm{ml}$ and the remaining volume of ethyl acetate is $(100-\mathrm{v}) \mathrm{ml}$. Mole fraction of methanol is calculated using the equation (1). In Table 1 mole fractions of components added in the mixtures are given and in Table 2 physical properties are solvents are presented.

$$
x=\frac{\left(\rho_{m} * \frac{V}{M_{m}}\right)}{\left(\rho_{m} * \frac{V}{M_{m}}+\rho_{e} * \frac{(100-V)}{M_{e}}\right)}
$$

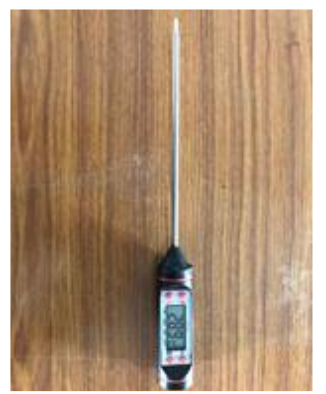

Figure 1. Digital Thermometer.

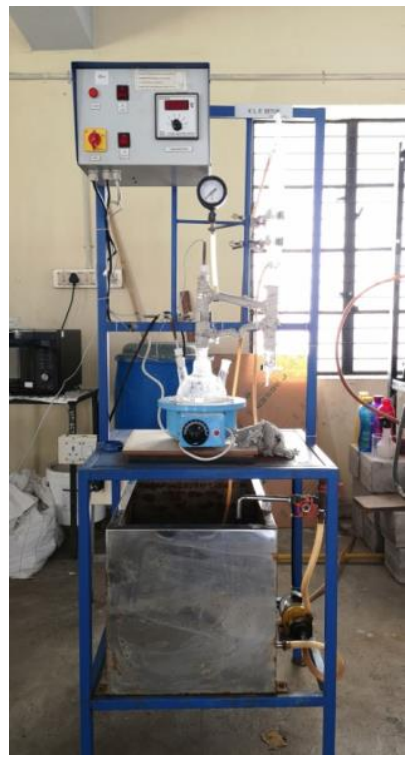

Figure 2. Othmer still experimental setup for measuring VLE data.

A specific gravity- mole fraction calibration curve was obtained for the system gravimetrically using a weighing machine of $0.001 \mathrm{~g}$ precision. The mixture was added to the still which was supplied with a heat source. The switch regulator ensures uniform heating. The temperature is noted from a digital thermometer as shown in the Figure 1. When equilibrium was established, vapour condensate and residue from the still were sampled.

Table 1. Amounts of methanol and ethyl acetate: solution number ( $S^{\prime}$ No. $)$, methanol mole fraction $\left(x_{m}\right)$, methanol volume $\left(v_{m}\right)$, and ethyl acetate volume $\left(v_{a}\right)$

\begin{tabular}{|c|c|c|c|}
\hline $\begin{array}{c}\text { Solution } \\
\text { No. }\end{array}$ & $\begin{array}{c}\text { Methanol mole } \\
\text { Fraction }\end{array}$ & $\begin{array}{c}\text { Methanol Volume, } \\
\mathrm{v}_{\mathrm{m}}\left(\mathrm{cm}^{3}\right)\end{array}$ & $\begin{array}{c}\text { Ethyl Acetate } \\
\text { Volume } \mathrm{v}_{\mathrm{a}} \\
=\left(100-\mathrm{v}_{\mathrm{m}}\right)\left(\mathrm{cm}^{3}\right)\end{array}$ \\
\hline 1 & 0.1 & 4.4 & 95.6 \\
2 & 0.2 & 9.4 & 90.6 \\
3 & 0.3 & 15.1 & 89.9 \\
4 & 0.4 & 21.7 & 78.3 \\
5 & 0.5 & 29.4 & 70.6 \\
6 & 0.6 & 38.4 & 61.6 \\
7 & 0.7 & 49.3 & 50.7 \\
8 & 0.8 & 62.5 & 37.5 \\
9 & 0.9 & 79 & 21 \\
\hline
\end{tabular}

Table 2. Physical properties of solvents.

\begin{tabular}{|c|c|c|c|c|}
\hline \multirow{2}{*}{ Components } & \multicolumn{2}{|c|}{ Boiling point $\left({ }^{\circ} \mathrm{C}\right)$} & \multicolumn{2}{c|}{ Specific Gravity } \\
\cline { 2 - 5 } & $\begin{array}{c}\text { Present } \\
\text { Work }\end{array}$ & Literature* & $\begin{array}{c}\text { Present } \\
\text { Work }\end{array}$ & Literature* \\
\hline Methanol & 66.1 & 64.8 & 0.789 & 0.791 \\
Ethyl Acetate & 79 & 77.2 & 0.886 & 0.902 \\
\hline
\end{tabular}

* Data obtained from NIST WebBook [25]

The concentrations of the residue and distillate were obtained from the calibration curve (Figure 3 ) using interpolation. The above procedure was repeated for the system with salt concentrations of $5 \%$ and $10 \% \mathrm{wt}$ of methanol. This was followed by the subsequent tabulation and interpretation. T$\mathrm{x}, \mathrm{y}$ and $\mathrm{x}-\mathrm{y}$ plots were plotted to find the azeotropic nature of the mixture at temperature and composition at $1 \mathrm{~atm}$.

\section{Consistency of VLE data}

The isobaric VLE data of methanol-ethyl acetate system is examined through a test of thermodynamic consistency [26], using Margules mathematical equations and Gibbs Duhem equation.

In this method, reduced $\mathrm{T}-\mathrm{x}, \mathrm{y}$ data can be obtained by the using the parameter excess Gibbs free energy as a function of composition. From the previous studies model parameters are obtained and the composition of vapour phase is calculated from the known composition of other phase at desired temperature and pressure within the valid range using Antoine equation,

$\log P_{i}^{\text {sat }}=A-\frac{B}{T+C}$

where, $A, B, C$ are Antoine constants, which are

Methanol

$A=5.20409$

Ethyl Acetate

$B=1581.341$

$A=4.22809$

$C=-33.5$

$B=1245.702$

$\mathrm{C}=-55.189$

Our purpose is to use the test for the consistency with respect to the Gibbs Duhem equation of a Txy data set. Equation (3) is written with experimental values, calculated by Equation (4).

$\frac{G^{E}}{R T}=x_{1} \ln \gamma_{1}+x_{2} \ln \gamma_{2}$

$\gamma_{i}=\frac{y_{i} P}{x_{i} P_{i}^{s a t}}$

The Margules equation is given by, 
$\ln \gamma_{1}=x_{2}^{2}\left[A_{12}+2\left(A_{21}-A_{12}\right) x_{1}\right]$

$\ln \gamma_{2}=x_{1}^{2}\left[A_{21}+2\left(A_{12}-A_{21}\right) x_{2}\right]$

If a data set is reduced so as to make the residuals in $\mathrm{G}^{\mathrm{E}} / \mathrm{RT}$ scatter about zero, then the derivative $\frac{\delta\left(\frac{G^{E}}{R T}\right)}{d x_{1}}$ is effectively zero, reducing (eq. 3) to:

$\delta \ln \frac{\gamma_{1}}{\gamma_{2}}=x_{1} \frac{d \ln \gamma_{1}^{*}}{d x_{1}}+x_{1} \frac{d \ln \gamma_{1}^{*}}{d x_{1}}$

\section{Results and Discussion}

Binary vapour liquid equilibrium (VLE) data for methanol (1) + ethyl acetate (2) at $101.325 \mathrm{kPa}$ is measured and the experimental data was calibrated for thermodynamic consistency using the calibration curve as shown in Figure 3. Calibration curve shows the minimum deviations and it can be used to calculate the mole fractions at specified specific gravities of the samples.

VLE data is plotted for the base case mixture containing the methanol (1) and ethyl acetate (2) and is shown in Figure 4. From this plot, it is observed that at $x_{1}=0.657$ we have the azeotrope. Objective of this study is to break the azeotrope or to shift the azeotrope towards the maximum separation point. Temperature versus composition data is plotted in Figure 5 and the azeotrope is identified at the temperature $65.9^{\circ} \mathrm{C}$ and at atmospheric pressure of 101.325 kpa.

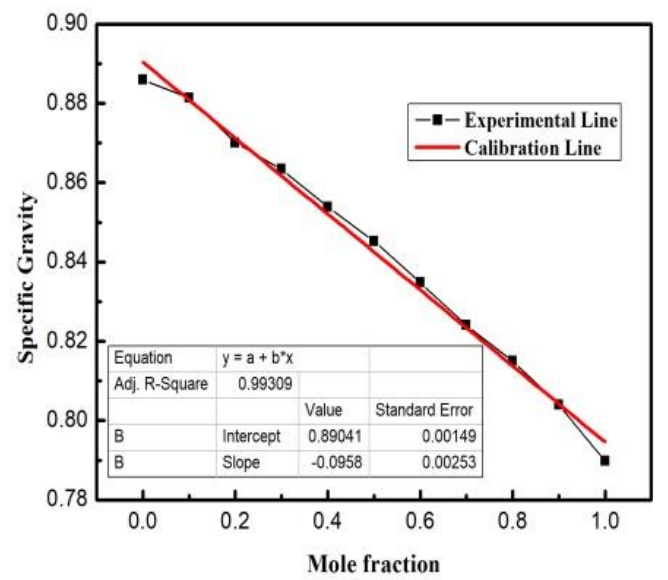

Figure 3. Calibration Curve for mole fraction of methanol.

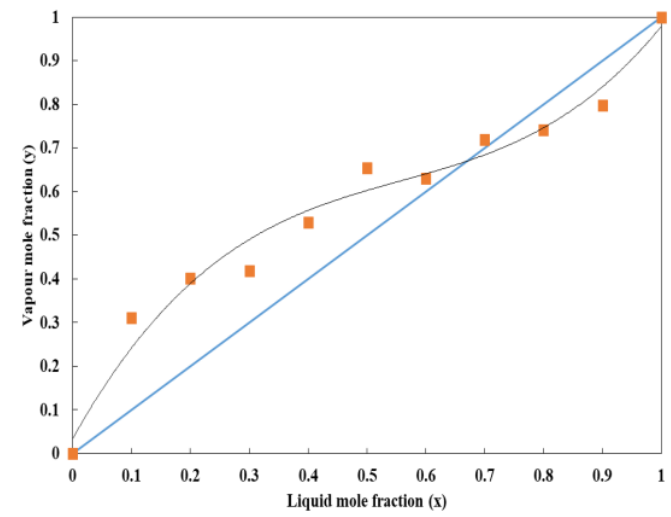

Figure 4. $x$-y curve for the base case for methanol.

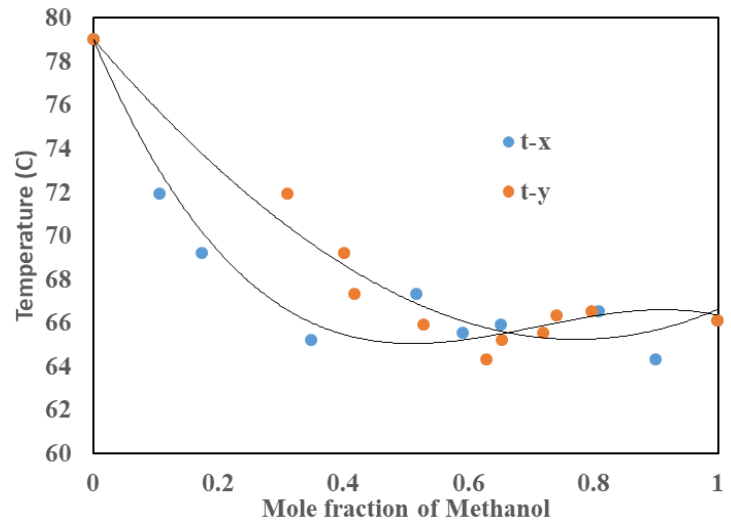

Figure 5. T-x,y Curve (0\% Entrainer)

\subsection{Effect of Ionic liquid [EMIM][CI]}

Effect of Ionic liquid (5\% [EMIM] [Cl]) on VLE is given in Figure 6. It is observed that azeotrope is shifted from $\mathrm{x}_{1}=$ 0.65 to $x_{1}=0.75$ (when compared to Figure 5). This change shows the improvement in breaking the azeotrope and it is a positive sign for the effective separation.

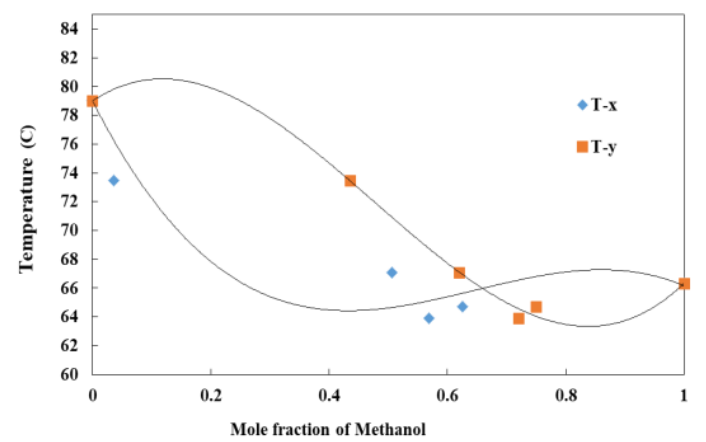

Figure 6. Effect of Ionic liquid (5\% [EMIM][Cl]) on VLE. $x$-axis shows mole fraction of methanol.

Effect of varying concentrations of ionic liquid i.e 5\% and $10 \%$ [EMIM] $[\mathrm{Cl}]$ on VLE is shown in Figure 7. It is observed that the increasing concentrations of ionic liquid $[\mathrm{EMIM}][\mathrm{Cl}]$ increased the separation efficiency of the azeotrope mixture from $\mathrm{x}_{1}=0.67$ to $\mathrm{x}_{1}=0.74$ and 0.86 respectively for $5 \%$ and $10 \%$ concentrations.

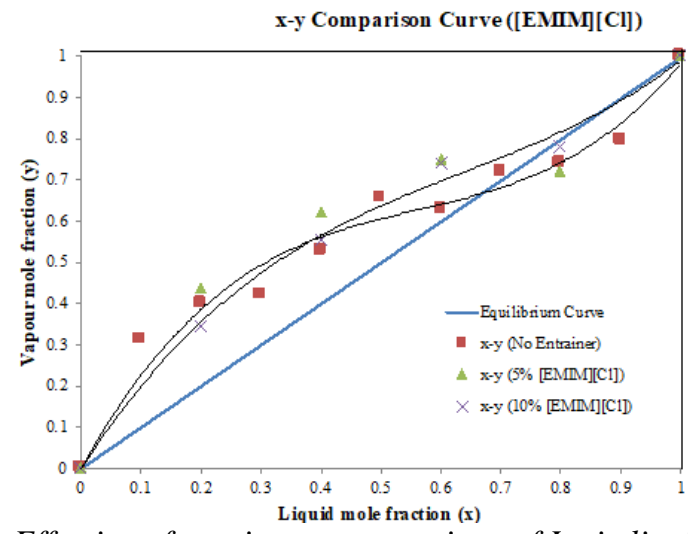

Figure 7. Effective of varying concentrations of Ionic liquid [EMIM][Cl] on VLE.

\subsection{Effect of Ionic Liquid [EMPyrr][Br]}

Similarly experiments were conducted to observe the effect of the second ionic liquid [EMPyrr][Br] on VLE 
behavior of Methanol (1) + Ethyl acetate (2) system. Effect of varying concentrations of the ionic liquid [EMPyrr] $[\mathrm{Br}]$ on VLE are shown in Figure 8. From Figure 8, it is evident that the azeotrope shifts from $\mathrm{x}_{1}=0.67$ to $0.74,0.85$ and almost 1.0 for the concentrations of ionic liquid [EMPyrr] $\mathrm{Br}]$ of $5 \%, 10 \%$ and $15 \%$ respectively. It shows that the separation efficiency is improved by breaking the azeotrope and the objective of the thermodynamic experiment has been considered as success.

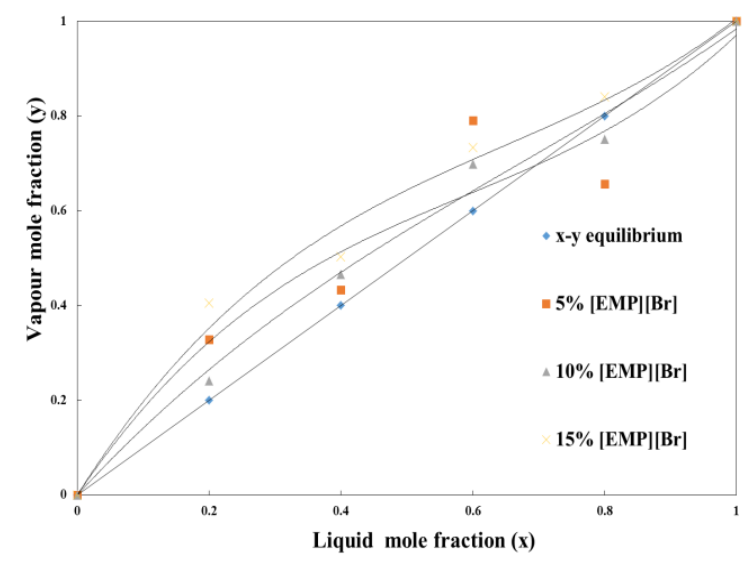

Figure 8. Effect of Ionic liquid [EMPyrr][Br] concentration on separation of Azeotrope.

Moreover, it is observed that with increasing concentration of ionic liquid, the azeotrope shifts to the right as was in the earlier case (Figure 7).

\subsection{Consistency Test for Binary VLE data}

The VLE data obtained for without entrainer was validated by consistency test using thermodynamic equations and it was found to vary from the Gibbs Duhem ideality relation. This variance can be either due to less data points for the system or the experimental error. Consistency test plot is shown in Figure 9. Scattering of the experimental points shows that the data is thermodynamically consistent.

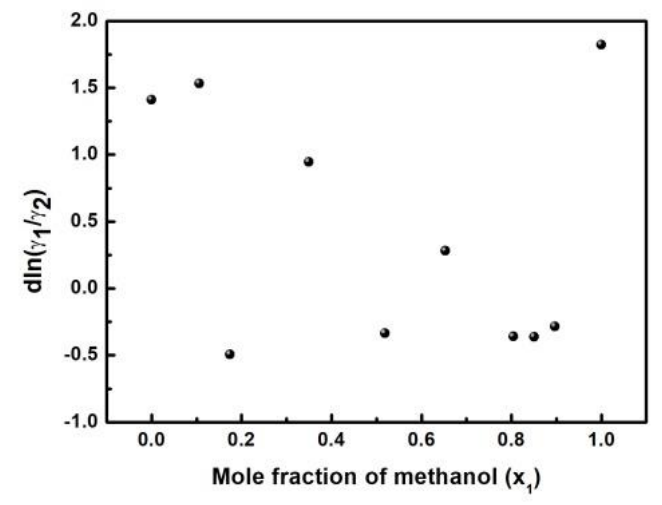

Figure 9. Thermodynamic consistency test.

\section{Conclusions}

Binary VLE data for Methanol and Ethyl acetate system containing the ionic liquids ([EMIM][Cl] and [EMPyrr][Br]) were obtained at $101.325 \mathrm{kpa}$. The ionic liquids (ILs) have shown significant effect on azeotropic system of Methanol and Ethylacetate. For the same concentrations of the ionic liquids [EMPyrr][Br] and [EMIM][Cl] has shown strong salting out effect on methanol. It shows that lesser amounts of the ionic liquid [EMIM][Cl] is enough to break the azeotrope. This strong salting out effect resulted in the complete disappearance of the azeotropic point. Thus these ionic liquids are suitable candidates for azeotropic distillation.

In addition to this, the recoverability of ionic liquid is expected to have significant advantage while using the same as entrainer for distillation. This characteristic feature will help towards making the distillation process more economic due to its reusability since the price of ionic liquids is speculated to come down substantially in the near future. This study helps in designing the industrially safe and energy efficient operations.

\section{Acknowledgements}

The authors are grateful to Vellore Institute of Technology for providing financial support through VIT seed grant money to successfully complete this research work.

$\begin{array}{ll}\begin{array}{ll}\text { Nomenclature } \\ {[\mathrm{EMIM}][\mathrm{Cl}]}\end{array} & \text { 1-ethyl-3-methylimidazolium Chloride } \\ {[\mathrm{EMPyr}][\mathrm{Br}]} & \text { 1-ethyl-1-methylpyrrolidinium Bromide } \\ \mathrm{V} & \text { Volume of sample, ml } \\ \mathrm{P} & \text { Total pressure, bar } \\ \mathrm{T} & \text { Temperature, } \mathrm{K} \\ \mathrm{G} & \text { Gibbs free energy } \\ \mathrm{R} & \text { Universal Gas Constant } \\ \mathrm{y} & \text { Vapour phase mole fraction } \\ \mathrm{X} & \text { Liquid phase mole fraction } \\ A_{12}, A_{21} & \text { Margules parameters } \\ \mathrm{M} & \text { Molecular weight, g/mol } \\ \mathrm{Greek} \text { Symbols } & \\ \rho & \text { Density, g/cm } \\ \gamma & \text { Theoretical Activity coefficient } \\ \gamma^{*} & \text { Experimental Activity coefficient }\end{array}$

\section{Subscripts and Superscripts}

m Methanol

e Ethyl acetate

sat Saturation

i Component name

\section{References}

[1] The Methanol Industry[online]. Available online:https://www.methanol.org/the-methanolindustry/ (accessed on 17 October 2018).

[2] P. G. Cifre, O. Badr, "Renewable hydrogen utilization for the production of methanol", Energy Convers. Manag.,48, 519-527, 2007.

[3] D. O. Hughes, Methanol: The chemical of the future. Chemsa 1980, 180-182.

[4] K. A. Ali, A. Z. Abdullah, A. R. Mohamed, "Recent development in catalytic technologies for methanol synthesis from renewable sources: A critical review", Renew. Sustain. Energy Rev., 44, 508-518, 2015.

[5] C. D. Silva, F. D. Castilhos, J. Oliveira, L. C. Filho,."Continuous production of soybean biodiesel with compressed ethanol in a micro tube reactor", Fuel Processing Technology.,91,.1274-1281, 2010.

[6] K.T. Tan, K.T. Lee, A.R. Mohamed. "Production of FAME by palm oil transesterification via supercritical methanol technology", Biomass And Bioenery.,33,.1096-1099, 2009.

[7] H. Imahara, J. Xin, S. Saka, "Effect of $\mathrm{CO}_{2} / \mathrm{N}_{2}$ addition to supercritical methanol on reactiveties and fuel 
qualities in biodiesel production", Fuel, 88, 1329-1332, 2009.

[8] J. Gmehling, J. Menke, K. Krafczy, Azeotropic data,Wiley-VCH Verlag; Weinheim, Germany, 2004; Part 1. J Gmehling, U Onken, Vapor-liquid equilibrium data collection; DECHEMA; Frankfurt, Germany, 1986, Vol 1, Part 2.

[10] Z. Lei, C. Dai, J. Zhu, B. Chen, "Extractive distillation with ionic liquids: a review", AICHEJ., 60, 33123329, 2014.

[11] J. Li, Z. Lei, C. Li, B. Chen, "Comments on special distillation processes", J. Korean J. Chem. Eng. Data., 22, 617-618, 2005

[12] N. Hilal, G. Yousef, P. Langston, "The reduction of extractive agent in extractive distillation and autoextractive distillation", Chem. Eng. Process., 41, 673679, 2001.

[13] M. Agarwal, V.G. Gaikar, "Extractive separations using hydrotropes", Sep. Technol. 2, 79-84, 1992.

[14] Q. Li, P. Liu, L. Cao, F.Wen, S. Zhang, B. Wang,"Vapor-liquid equilibrium for tetrahydrofuran + methanol + tetrafluoroborate-based ionic liquids at101.3 kPa", Fluid Phase Equilibria., 360, 439-444, 2013.

[15] Q. Li, F. Xing, Z. Lei, B. Wang, Q. Chang, "Isobaric vapor-liquid equilibrium for isopropanol + water +1 ethyl-3-methylimidazolium tetrafluoroborate", $J$. Chem.Eng. Data., 53, 275-279, 2008.

[16] Q. Li, J. Zhang, Z. Lei, J. Zhu, J. Zhu, X. Huang, "Selection of ionic liquids as entrainers for the separation of ethyl acetate and ethanol", J. Ind. Eng. Chem. Res.,48, 9006-9012, 2009.

[17] Z. Li, Q. Li, R. Qiao, K. Zhang, "Isobaric vapor-liquid Equilibrium for methanol+methyl ethyl ketone $p$ bis(trifluoromethylsulfonyl)imide-based ionic liquids at 101.3 kPa", Fluid Phase Equilibria. 427, 90-96, 2016.
[18] J. Zhu, J. Chen, C. Li, W. Fei, "Study on separation of 1-hexane and trans 3-hexene using ionic liquids", Fluid Phase Equilibria., 247, 102-106, 2006.

[19] A. Heintz, "Recent developments in thermodynamics and thermophysics of nonaqueous mixtures containing ionic liquids. A review", J. Chem. Thermodyn., 37, 525$535,2005$.

[20] N.K. Marsh, A.J. Boxall, R. Lichtenthaler, "Room temperature ionic liquids and their mixtures-A review", Flid Phase Equilibria., 219, 93-98, 2004.

[21] J. Zha, C. Dong, CX. Li, H. Meng, Z.H. Wang, "Isobaric -liquid equilibria for ethanol-water system containing different ionic liquids at atmospheric pressure," Fluid Phase Equilibria., 242, 147-153, 2006.

[22] L. Zhang, J. Han, D. Deng, J. Ji, "Selection of ionic liquids as entrainers for separation of water and 2propanol", Fluid Phase Equilibria. 255, 179-185, 2007.

[23] A V Orchilles, P J Miguel, E Vercher, A. Martinez, "Ionic liquids as entrainers in extractive distillation: isobaric vapor-liquid equilibria for acetone + ethanol+1-ethyl-3-methylimidazolium trifluoromthanesulfonate", J., Chem. Eng. Data., 52, 141-147, 2007.

[24] Z. Zhang, F. Pan, Q. Zhang, T. Zhang, L. Zhang, K. Wu, W. Li, "Isobaric Vapor-Liquid Equilibria for Ethyl Acetate + Methanol + Ionic Liquids Ternary Systems at 101.3 kPa", J. Chem. Eng. Data., 61, 772- 779, 2016.

[25] NIST Chemistry Web Book (https://webbook.nist.gov/) (last accessed, October 2018).

[26] J. M. Smith, H. C. Van Ness, and M. M. Abbott, Introduction to Chemical Engineering Thermodynamics. 7th Ed., McGraw-Hill, Boston, 2005. 